Ambiente \& Água - An Interdisciplinary Journal of Applied Science
ISSN 1980-993X - doi:10.4136/1980-993X
www.ambi-agua.net
E-mail: ambi.agua@gmail.com

\title{
Caracterização morfométrica das sub-bacias no município de Xapuri: subsídios à gestão territorial na Amazônia Ocidental
}

\author{
doi: 10.4136/ambi-agua.1426
}

Received: 17 Jun. 2014; Accepted: 02 Mar 2015

\section{Éllen Albuquerque Abud ${ }^{1 *}$; João Luiz Lani²; Edson Alves de Araújo ${ }^{3}$; Eufran Ferreira do Amaral ${ }^{4}$; Nilson Gomes Bardales ${ }^{5}$; Elpídio Inácio Fernandes Filho ${ }^{2}$}

\footnotetext{
${ }^{1}$ Secretaria de Estado de Extensão Agro-florestal e Produção Familiar, Rio Branco, AC, Brasil

${ }^{2}$ Universidade Federal de Viçosa (UFV), Viçosa, MG, Brasil

${ }^{3}$ Universidade Federal do Acre (UFAC), Rio Branco, AC, Brasil

${ }^{4}$ Empresa Brasileira de Pesquisa Agropecuária (EMBRAPA), Rio Branco, AC, Brasil

${ }^{5}$ Instituto de Mudanças Climáticas e Regulação de Serviços Ambientais, Rio Branco, AC, Brasil

Autor correspondente: e-mail: ellenabud@ hotmail.com,

lani@ufv.br, earaujo.ac@gmail.com, eufranferreiraamaral@gmail.com, nilsonbard@yahoo.com.br, elpidio@ufv.br
}

\section{RESUMO}

O trabalho objetivou a caracterização morfométrica das sub-bacias hidrográficas que ocorrem no município de Xapuri e a construção de um modelo explicativo do nível de impacto e resiliência das bacias hidrográficas do município com ênfase na estruturação de uma ferramenta para uso por não especialistas para subsidiar a tomada de decisão sobre a ocupação do território. A área de estudo está localizada no Estado do Acre e apresenta quatro sub-bacias: Alto Acre, rio Xapuri, Xipamanu e Riozinho do Rola. Realizou-se o levantamento cartográfico da área, as características morfométricas e de uso e cobertura da terra que resultou no zoneamento pedo-hidrográfico do município. As sub-bacias Xapuri, Xipamanu e Riozinho do Rôla apresentaram densidade e ordem de drenagem que indicam uma baixa eficiência de drenagem, porém o Alto Acre apresentou ordem de drenagem elevada (nona ordem) contrariando os índices geométricos e a densidade de drenagem, sendo considerada eficiente a drenagem. Ocorre no município de Xapuri alteração considerável nas áreas de preservação permanente e já se tem uma conversão em áreas de menor resiliência sujeitas a impactos associados a uma alta sensibilidade. O zoneamento pedo-hidrográfico permite visualizar o município num contexto de gestão territorial por meio de um enfoque ecossistêmico e de uma visão qualitativa dos potenciais e das fragilidades.

Palavras-chave: ordenamento territorial, recursos hídricos, zoneamento pedo-hidrográfico.

\section{Morphometric characterization of sub-basins in the municipality of Xapuri: subsidies to land management in the Western Amazon}

\section{ABSTRACT}

This work morphometrically characterized watersheds that occur in the municipality of Xapuri and constructed a model that explains the extent of watershed impact and resilience. 
Emphasis was given to provide a decision-making tool for non-specialists. The study area is located in the State of Acre and has four sub-basins: Alto Acre, Rio Xapuri, Xipamanu and Riozinho do Rola. A cartographic survey was conducted, to include the morphometric characteristics of the area and land use and cover features that resulted in the soilhydrographic zoning of the municipality. Sub-basins Xapuri, Xipamanu and Riozinho do Rôla revealed drainage densities and orders that indicate low drainage efficiency, while Alto Acre presented high drainage orders (ninth order) and densities, contrary the geometric indices and drainage densities, and is considered to have efficient drainage. Considerable alterations in permanent preservation areas occur in the municipality of Xapuri, with conversion to less resilient areas highly sensitive to impacts. The soil-hydrographic zoning assists in visualizing the municipality in a land management context through an ecosystem approach and a qualitative view of the possibilities and weaknesses.

Keywords: Hydrological resources, soil-hydrographic zoning, territorial ordering.

\section{INTRODUÇÃO}

O município de Xapuri destaca-se no Estado do Acre e na história da sustentabilidade ambiental como berço do socioambientalismo. O governo do Estado tem investido em estudos e levantamentos de aspectos socioeconômicos, culturais e ambientais, como o Zoneamento Ecológico-Econômico em suas fases I e II (Acre, 2000; 2006) e o Ordenamento Territorial Local a nível municipal (Acre, 2010). O estudo dessa unidade de gestão pode servir de auxílio no planejamento estratégico do município.

A Política Estadual de Recursos Hídricos do Acre definiu como um de seus instrumentos de gestão dos recursos hídricos o Plano Estadual de Recursos Hídricos (Acre, 2012). O referido plano propôs a divisão do Estado em seis unidades de gestão, uma delas compreende a bacia do Rio Acre. Nas áreas vulneráveis e de interesse estratégico serão elaborados futuramente os Planos de Bacia ou de Desenvolvimento Estratégico, por meio de uma Agenda 21 da Bacia Hidrográfica, pelos respectivos Comitês de Bacias Hidrográficas, quando implantados (Almeida et al., 2009).

A bacia do Rio Acre tem suas cabeceiras na Reserva Extrativista Chico Mendes e concentra vários pontos de ação antrópica (principalmente próximas a sua foz) que podem culminar em mudanças significativas no regime hidrológico, alterando a qualidade das águas e o regime sazonal e, ou intermitente dos igarapés (Macêdo et al., 2013). Esse fenômeno pode resultar em enchentes periódicas, considerando que cada vez mais eventos extremos de enchentes e seca estão ocorrendo com maior frequência na região (Sena et al., 2012a, Sena, 2012b).

Para fins de estudo e caracterização morfométrica de bacias hidrográficas Christofoletti (1999) afirma que geoprocessamento e o processamento digital constituem-se em ferramentas que auxiliam na análise das informações espaciais georreferenciadas. Silva e Zaidan (2004) citam que a principal característica do geoprocessamento é permitir a investigação sistemática das propriedades e relações posicionais dos eventos e entidades representados em uma base de dados georreferenciados, transformando dados em informação destinada ao apoio à tomada de decisão.

Entender as inter-relações existentes envolvidas nos processos hidrológicos de uma bacia hidrográfica depende da expressão da dinâmica da água e de uso da terra em termos qualitativos e quantitativos, de forma a qualificarem as alterações ambientais (Alves e Castro, 2003; Resende et al., 2007).

Tonello et al. (2006) mencionam que a quantificação da disponibilidade hídrica serve de base para o planejamento dos recursos hídricos quando todas as características de forma, processos e inter-relações existentes são expressos de forma quantitativa; e os índices são tratados de maneira conjunta. 
Segundo Tucci (1993) a bacia hidrográfica é o elemento fundamental de análise do ciclo hidrológico, principalmente na sua fase terrestre. Áreas que apresentam argila expansiva, comum no Estado, podem afetar a infiltração da água no solo e contribuir para a erosão, além de influenciar na flutuação acentuada nas cotas fluviométricas dos rios, o que é um fenômeno observado no Acre (Rezende e Machado, 1988; Macedo et al., 2013; Schaefer, 2013).

A sensibilidade ambiental (reação do sistema a mudanças em função de impactos) pode ser relacionada à capacidade de resiliência do sistema podendo, uma ou outra, ser utilizada em uma matriz de gerenciamento ambiental.

O trabalho objetivou a caracterização morfométrica das sub-bacias hidrográficas que ocorrem no município de Xapuri, considerando suas características fisiográficas e o uso e cobertura atual da terra, com o uso de ferramentas de geoprocessamento; e construir um modelo explicativo do nível de impacto e resiliência das bacias hidrográficas do município com ênfase a estruturação de uma ferramenta para uso por não especialistas para subsidiar a tomada de decisão sobre a ocupação do território.

\section{MATERIAIS E MÉTODO}

A área de estudo corresponde as sub-bacias que se encontram dentro dos limites do município de Xapuri. Este se localiza no Estado do Acre, na regional do Alto Acre. Foi possível identificar as seguintes sub-bacias: Riozinho do Rôla, Xapuri, Alto Acre e Xipamanu (Figura 1).

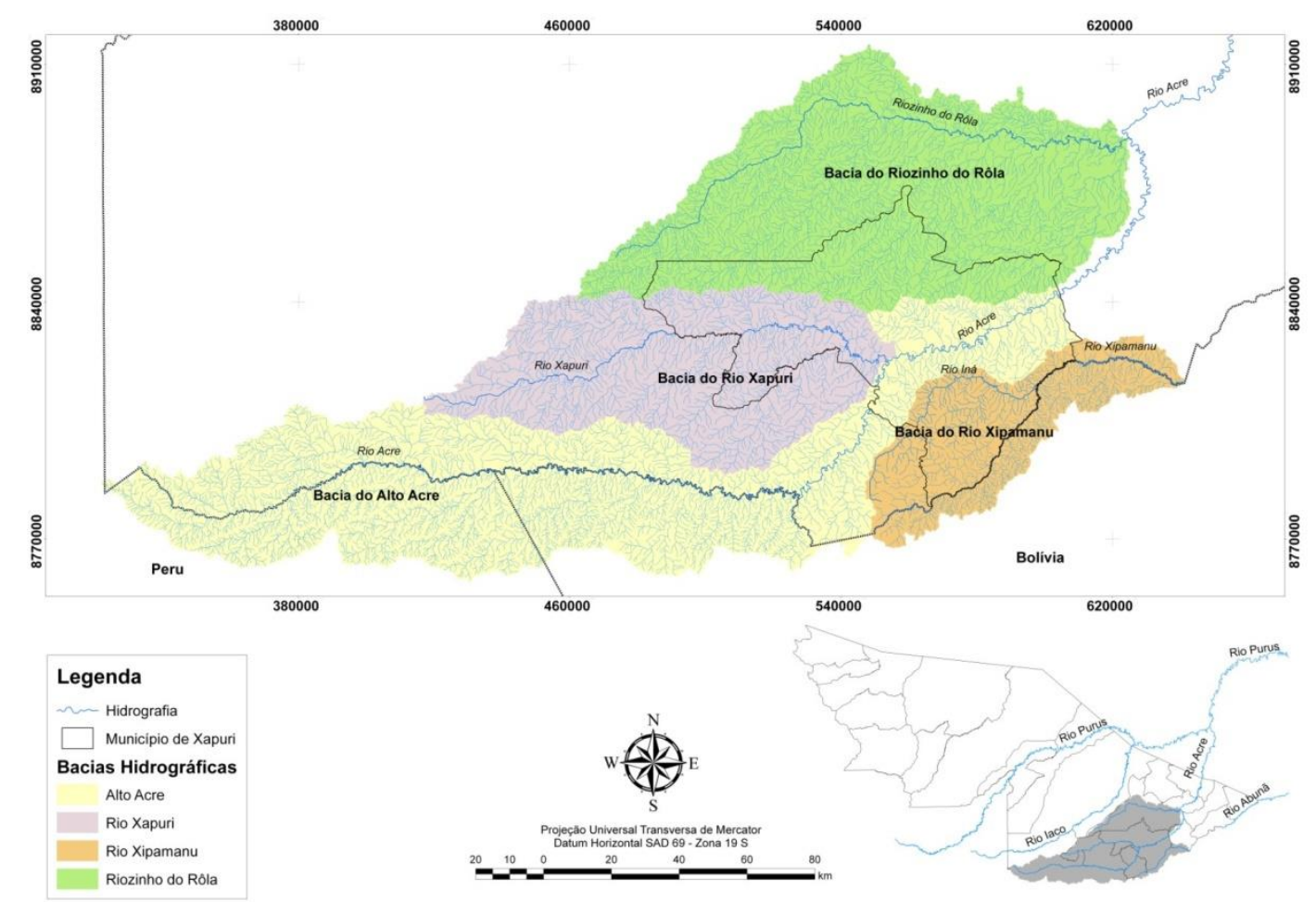

Figura 1. Localização das sub-bacias encontradas dentro dos limites do município de Xapuri, Acre.

A ocupação populacional segue o mesmo modelo do restante da Amazônia. O crescimento das cidades inicia-se nas margens dos rios em direção as terras mais altas. A cidade de Xapuri localiza-se na foz do rio Xapuri que desemboca no rio Acre. Na cidade concentra aproximadamente $64 \%$ da população do município que é de 16.016 habitantes (IBGE, 2010). 
A maior área do município de Xapuri é ocupada pela sub-bacia do Riozinho do Rôla (165.777,4 ha) o que corresponde a 31\% da área do município. Nesta sub-bacia encontra-se o maior número de nascentes que estão parcialmente preservadas pela Reserva Extrativista (RESEX) Chico Mendes.

As sub-bacias dos rios Xapuri (133.224,4 ha) e Acre (Alto Acre) (134.906,3 ha) correspondem ambas a aproximadamente $25 \%$ e a do rio Xipamanu (100.787,1 ha) ocupa $18 \%$ da área de estudo.

A base cartográfica foi elaborada a partir dos novos limites municipais do Estado do Acre, sendo utilizados os dados de hidrografia, curvas de nível, comunidades, sedes municipais, rede viária, na escala de 1:100.000 (Acre, 2006).

Para elaborar o Modelo Digital de Elevação Hidrologicamente Consistente (MDEHC) utilizou-se imagens SRTM reamostradas para $50 \mathrm{~m}$, de acordo com a área mínima mapeável em escala 1:100.000 e eliminou-se erros sistemáticos da imagem, como as depressões espúrias. A base de dados e as análises foram geradas utilizando o sistema de informações geográficas (SIG), por meio do software ArcGis 9.3 e a extensão Hydrology Tools.

O MDEHC foi utilizado como entrada para a elaboração dos mapas de declividade e altitude. As classes de declividade foram separadas e reclassificadas em seis intervalos distintos (Santos et al., 2013). A declividade média foi obtida com o uso da ferramenta Zonal Statistics as Table.

Com a delimitação da área das sub-bacias, obtiveram-se diferentes características morfométricas, tais como: coeficiente de compacidade $(\mathrm{Kc})$; fator de forma; índice de circularidade; ordem dos cursos d' água; densidade de drenagem e padrão de drenagem.

Para a análise fisiográfica foram utilizadas imagens TM/LANDSAT 02/67 e 02/68 com composição colorida das bandas 3 (vermelho), 4 (vermelho próximo) e 5 (infravermelho médio), ano de 2010 e imagem do SRTM (Shuttle Radar Topography Mission), ano de 2006, com pixel de $90 \mathrm{~m}$.

O uso e cobertura da terra foram obtidos por meio da estratificação de sete categorias: floresta, capoeira, agricultura, pastagem, solo exposto, mancha urbana e corpos d'água. Além destas, foram utilizadas imagens Formosat com bandas multiespectrais (coloridas) de 8 metros de resolução, compostas por 4 bandas espectrais, a saber: infravermelho próximo, vermelho, verde e azul, do acervo da Secretaria de Meio Ambiente do Estado do Acre.

Para delimitação das áreas de preservação, foi considerada uma zona-tampão conforme o Código Florestal (Lei ${ }^{\circ}$ 12.651/2012), que dispõe sobre parâmetros, definições e limites de áreas de preservação permanente.

No zoneamento pedo-hidrográfico a definição de sensibilidade foi o resultado do cruzamento das informações de morfometria e de desmatamento, sendo definidas três classes de sensibilidade (alta, média e baixa). Na definição da resiliência foi utilizada a base de informações de pedoambientes, sendo definidas três classes de acordo com as características dos solos predominantes (alta média e baixa).

As curvas de correspondência entre índices de impacto dos indicadores e valores de utilidade foram expressos em equações multicoeficientes (desmatamento, morfometria, uso da terra e solos) derivadas caso a caso, com ajuste mínimo correspondente a $\mathrm{R}^{2}=0,95$ (Hyams, 1995). As equações e coeficientes foram inseridas nas matrizes de ponderação e vinculadas ao índice de impacto, traduzindo-os diretamente em valores de utilidade para expressão gráfica e calculo do índice do zoneamento pedo-hidrográfico.

O uso e cobertura da terra foram reclassificados de acordo com o nível de intensidade, assim como: floresta (10), capoeira (8), agricultura (6), pastagem (4), solo exposto (2), mancha urbana (1) e corpos d'água (5). Com o grau de resiliência e de sensibilidade de cada unidade territorial foram definidas nove classes de gerenciamento ambiental.

Para os níveis de resiliência e sensibilidade foram atribuídos os seguintes pesos: 
alta resiliência com baixa sensibilidade -10 ;

alta resiliência com média sensibilidade -8 ;

alta resiliência com alta sensibilidade -5 ;

média resiliência com baixa sensibilidade - 9;

média resiliência com média sensibilidade -7 ;

média resiliência com alta sensibilidade -5 ;

baixa resiliência com baixa sensibilidade -4 ;

baixa resiliência com média sensibilidade -2 e

baixa resiliência com alta sensibilidade -1 .

O uso atual da terra integrado com as classes de gerenciamento ambiental consolidou cinco zonas de unidades pedo-hidrográficas que se constituem na base síntese da análise do território. As seguintes zonas são: sem impacto, baixo, médio, alto e muito alto impacto nas unidades pedo-hidrográficas.

\section{RESULTADOS E DISCUSSÃO}

A morfometria das seguintes sub-bacias: Alto Acre, Riozinho do Rôla, Xapuri e Xipamanu foi representada pelas características e índices apresentados na Tabela 1.

A maior área do município de Xapuri é ocupada pela sub-bacia do Riozinho do Rôla (165.777,4 ha) o que corresponde a 31\%. Nesta sub-bacia encontra-se o maior número de nascentes que estão parcialmente preservadas pela RESEX Chico Mendes.

A declividade em ambas as sub-bacias apresentaram predominância do relevo suave ondulado, seguido das classes ondulado e plano. A declividade influencia a relação entre a precipitação e o deflúvio da bacia hidrográfica, sobretudo devido ao aumento da velocidade de escoamento superficial, reduzindo a possibilidade da infiltração no solo (Cardoso et al., 2006). Em algumas áreas da sub-bacia Xapuri, Riozinho do Rôla e Alto Acre apresentam relevo ondulado, mas são áreas localizadas dentro da RESEX Chico Mendes, a alta declividade pode ser compensada pela boa cobertura vegetal.

A principal classe de solo encontrada nas sub-bacias dentro do município de Xapuri pertence aos Argissolos (Acre, 2006; 2010). De acordo com estudos de Ranzani (1980), em solos da Amazônia, os Argissolos tendem a apresentar índice de erodibilidade mais elevado do que em Latossolos. Essa informação aliada ao fato de que os Argissolos descritos na área de Xapuri apresentam maior quantidade de areia fina no horizonte superficial e maior conteúdo de argila em subsuperfície resulta na dificuldade de infiltração em profundidade e favorece o escoamento superficial.

Portanto, a cobertura vegetal exerce papel fundamental na diminuição da erosão superficial e permite a infiltração da água. A associação da cobertura vegetal, declividade e características físicas solo tornam-se fatores importantes na tomada de decisão em relação ao manejo adequado de cada sub-bacia.

A altitude nas sub-bacias variou de $426 \mathrm{~m}$ na sub-bacia do Alto Acre e a mínima de 140 m no Riozinho do Rôla, sendo a altitude média de 222 a 280 m respectivamente. Quanto maior a altitude da bacia menor a quantidade de energia solar que o ambiente recebe e, portanto, menos energia estará disponível (Tonello, 2005).

O comportamento hidrológico de uma bacia hidrográfica depende, além das características geomorfológicas, da ação antrópica sobre o meio; uma vez que, ao intervir no meio natural, o homem acaba interferindo nos processos do ciclo hidrológico (Tonello, 2005). 
Tabela 1. Características morfométricas das sub-bacias do município de Xapuri, Acre.

\begin{tabular}{|c|c|c|c|c|c|}
\hline \multirow{2}{*}{ Área de Drenagem } & \multirow{2}{*}{ Unidade } & \multicolumn{4}{|c|}{ Sub-bacia } \\
\hline & & Riozinho do Rôla $^{(1)}$ & Rio Xapuri & Rio Xipamanu & Alto Acre \\
\hline Área & ha & $763.695,90$ & $480.653,02$ & $250.197,66$ & $942.930,89$ \\
\hline Perímetro & $\mathrm{km}$ & 654,20 & 556,14 & 357,32 & $1.076,18$ \\
\hline Área Drenagem & $\mathrm{km}^{2}$ & $7.637,00$ & $4.806,53$ & $2.501,98$ & $9.429,31$ \\
\hline \multicolumn{6}{|c|}{ Forma da Bacia } \\
\hline Fator de Forma (Kf) & - & 0,27 & 0,24 & 0,23 & 0,11 \\
\hline Índice de Circularidade (IC) & - & 0,22 & 0,20 & 0,25 & 0,10 \\
\hline $\begin{array}{l}\text { Coeficiente de Compacidade } \\
(\mathrm{Kc})\end{array}$ & - & 2,10 & 2,25 & 2,00 & 3,10 \\
\hline \multicolumn{6}{|c|}{ Relevo da Bacia } \\
\hline Declividade Máxima & $\%$ & 36,07 & 23,24 & 26,98 & 29,36 \\
\hline Declividade Média & $\%$ & 5,55 & 6,16 & 5,15 & 5,74 \\
\hline Declividade Mínima & $\%$ & 0,06 & 0,00 & 0,00 & 0,00 \\
\hline Altitude Máxima & $\mathrm{m}$ & 340 & 358 & 313 & 426 \\
\hline Altitude Média & $\mathrm{m}$ & 222 & 262 & 222 & 280 \\
\hline Altitude Mínima & $\mathrm{m}$ & 140 & 160 & 142 & 146 \\
\hline Amplitude Altimétrica & $\mathrm{m}$ & 200 & 198 & 171 & 280 \\
\hline \multicolumn{6}{|c|}{ Sistema de Drenagem } \\
\hline Ordem & - & 6 & 4 & 4 & 9 \\
\hline Densidade de Drenagem (Dd) & $\mathrm{km} \cdot \mathrm{km}^{-2}$ & 0,93 & 0,82 & 0,96 & 0,91 \\
\hline Padrão de Drenagem & - & Dendrítica & Dendrítica & Dendrítica & Dendrítica \\
\hline Sinuosidade do curso d' água & - & 1,82 & 1,66 & 1,82 & 2,87 \\
\hline Comprimento total dos canais & $\mathrm{km}$ & $7.111,07$ & $3.934,48$ & $2.390,40$ & $8.570,42$ \\
\hline $\begin{array}{l}\text { Comprimento do eixo } \\
\text { principal (reta) }\end{array}$ & $\mathrm{km}$ & 169,42 & 140,20 & 103,44 & 288,40 \\
\hline $\begin{array}{l}\text { Comprimento do canal } \\
\text { principal }\end{array}$ & $\mathrm{km}$ & 307,82 & 233,00 & 188,44 & 826,45 \\
\hline
\end{tabular}

${ }^{(1)}$ Fonte: Macêdo (2010).

As sub-bacias foram classificadas como endorreicas e dentre as sub-bacias identificadas a do Alto Acre representa a maior área de drenagem com $9.429,31 \mathrm{~km}^{2}$, seguido do Riozinho do Rôla, Xapuri e Xipamanu. A quantidade de água que atinge os cursos fluviais está na dependência do tamanho real da área ocupada pela sub-bacia e outras variáveis, sendo a principal variável para calcular os índices morfométricos (Christofoletti, 1974).

$\mathrm{O}$ fator forma $(\mathrm{Kf})$ das sub-bacias apresentou-se semelhantes variando entre 0,23 (Xipamanu) a 0,27 (Riozinho do Rôla), com exceção do Alto Acre com 0,11. O fator relaciona a forma da sub-bacia com a de um retângulo, podendo ser influenciada por algumas características, principalmente a geologia (Villela e Mattos, 1975). Podem atuar também sobre alguns processos hidrológicos ou sobre o comportamento hidrológico da bacia (Cardoso et al., 2006).

Pode-se inferir a cerca do fator forma, que as sub-bacias possuem poucas chances de sofrerem inundações e a sub-bacia Alto Acre está menos sujeita a esse fenômeno do que as demais, dentro das condições normais de precipitação. Esse fato é corroborado pelo índice de circularidade (IC), com valores menor que 0,26 (quanto mais próximo do valor 1,00, mais parecido com a forma circular), e o coeficiente de compacidade (Kc), maior que 2,00 
(quanto maior o valor mais irregular) os quais apresentaram o mesmo comportamento do fator de forma, com semelhanças entre as sub-bacias Riozinho do Rôla, Xapuri e Xipamanu, com exceção do Alto Acre.

De acordo com os índices geométricos a forma superficial é importante na determinação do tempo de concentração da água, ou seja, tempo necessário para que toda a bacia contribua para a sua saída após precipitação. Pode-se inferir que as sub-bacias são alongadas, não circulares e o escoamento direto da chuva não se concentra rapidamente, amenizando a influência da intensidade das chuvas, diminuindo assim a variação no curso d'água (Torres et al., 2009), se mantidas constantes outras características (Villela e Mattos, 1975). Além disso, por ser alongada, menor a possibilidade de chuvas intensas cobrindo simultaneamente toda a extensão da bacia. Importante saliente, que além desses índices, outros fatores estão relacionados às enchentes, como: cobertura florestal, duração da chuva e permeabilidade do solo (Macêdo, 2010).

A densidade de drenagem (Dd) obtida nas sub-bacias do Riozinho do Rôla, Xipamanu, Xapuri e Alto Acre apresentaram-se semelhantes com 0,93, 0,96, 0,82 e 0,91 km. $\mathrm{km}^{-2}$ respectivamente. De acordo com Villela e Mattos (1975) a densidade pode variar de 0,5 $\mathrm{km} . \mathrm{km}^{-2}$ em bacias de drenagem pobre a $3,5 \mathrm{~km} . \mathrm{km}^{-2}$ ou mais nas bacias mais bem drenadas, assim as seguintes sub-bacias são consideradas moderadamente drenadas. A sub-bacia do Alto Acre se comportou de forma diferente, com densidade menor $0,45 \mathrm{~km} \cdot \mathrm{km}^{-2}$, baixa eficiência na drenagem.

Segundo Cardoso et al. (2006), a Dd indica a maior ou menor velocidade com que a água deixa a bacia hidrográfica, sendo assim, o índice indica o grau de desenvolvimento do sistema de drenagem, ou seja, fornece uma indicação da eficiência da drenagem da bacia.

De acordo com a hierarquia de canais de Strahler (1957), as sub-bacias Xapuri e Xipamanu apresentaram grau de ramificação de quarta ordem, Riozinho do Rôla de sexta ordem e o Alto Acre nona ordem, considerada como a mais ramificada, possui maior eficiência no sistema de drenagem de acordo com a sua hierarquia.

Porém, segundo Teodoro et al. (2007) quanto maior a ordem de drenagem, maiores as possibilidades de cheias e inundações, por proporcionarem uma drenagem mais rápida e uma aumento também mais rápido da vazão do curso d’água principal. A bacia do Alto Acre apresentou a maior ordem, contrariando os índices geométricos que indicam poucas chances de inundação e a densidade de drenagem que indicou baixa eficiência na drenagem.

O padrão de drenagem de todas as sub-bacias é enquadrado como dentrítico ou arborescente. De acordo com Christofoletti (1974), esse padrão é tipicamente desenvolvido sobre rochas de resistência uniforme, ou em estruturas sedimentares horizontais, como ocorre na área de estudo, com presença de argilitos, siltitos e arenitos com estratificação paralela (Brasil, 1976).

As características do padrão de drenagem refletem o processo morfogenético do terreno na escultura da paisagem (Christofoletti, 1974), repercutem no comportamento hidrológico e litológico de cada unidade de solo. Em locais onde a infiltração é difícil, ocorre maior escoamento superficial, sendo possível maior esculturação da rede hidrográfica, tendo como consequência uma densidade de drenagem mais alta (Pissarra et al., 2004).

As características do padrão de drenagem diferenciaram-se entre as unidades de solos, o mesmo verificado por Manzoli Jr. (1990) e Demattê e Demétrio (1996). Isto se deve ao fato de que, nos Latossolos, o intemperismo é mais avançado, sendo a superfície desenvolvida sob condição de maior permeabilidade, manifestando-se, portanto, uma drenagem menos dissecada nas partes mais baixas da bacia hidrográfica (Pissarra et al., 2004).

As APP's ocupam 29.322,9 ha que corresponde a 5,6\% do território de Xapuri. Encontra com $25,2 \%$ de sua extensão convertida em outros usos e a maior extensão desta área de conversão é de pastagens, sendo utilizada para agricultura menos de 5\%. As capoeiras 
ocupam a segunda maior extensão e reforçam a dinâmica de uso nas margens de rios e igarapés com pequenos roçados de agricultura familiar.

$\mathrm{Na}$ maior parte do município (Tabela 2 e Figura 2) apresentou muito baixo e baixo impacto nas unidades pedo-hidrográficas, em função da cobertura florestal dos solos que possuem também maior resiliência. Nestas áreas devem ser priorizadas ações de conservação e valorização da floresta em pé.

Tabela 2. Classes pedo-hidrográficas do município de Xapuri,

Acre.

\begin{tabular}{lcc}
\hline Classes pedo-hidrográficas & hectares (ha) & $\%$ \\
\hline Muito alto impacto & $45.574,2$ & 8,6 \\
Alto impacto & $28.645,6$ & 5,4 \\
Médio impacto & $4.968,9$ & 0,9 \\
Baixo impacto & $173.508,1$ & 32,6 \\
Muito baixo impacto & $280.291,2$ & 52,6 \\
\hline TOTAL & $532.988,0$ & 100,0 \\
\hline
\end{tabular}

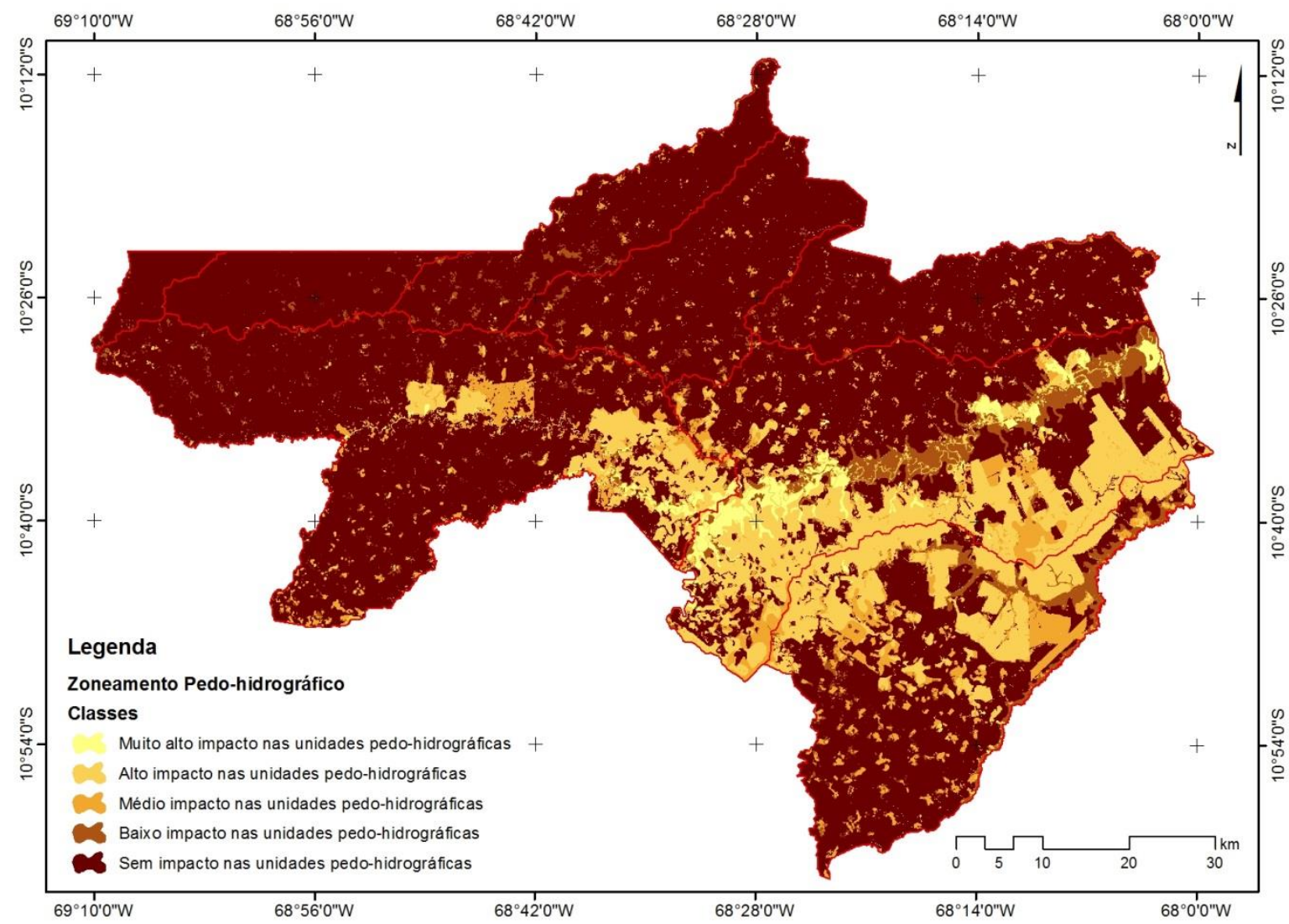

Figura 2. Zoneamento pedo-hidrográfico do município de Xapuri, Estado do Acre.

As áreas de alto e muito alto impacto somam 14\% do território e nestas áreas devem ser priorizadas ações de recuperação e de inserção de usos mais sustentáveis. As áreas de médio impacto são aquelas nas quais ocorre um uso adequado à capacidade de resiliência das áreas e a sensibilidade das bacias. Ocupam $0,9 \%$ do território, evidenciando a utilização do solo com atividades não sustentáveis. 


\section{CONCLUSÃO}

As sub-bacias Xapuri, Xipamanu e Riozinho do Rôla apresentaram densidade e ordem de drenagem que indicam uma baixa eficiência de drenagem, porém o Alto Acre apresentou ordem de drenagem elevada (nona ordem) contrariando os índices geométricos e a densidade de drenagem, sendo considerado de drenagem eficiente.

No município de Xapuri ocorre alteração considerável nas áreas de preservação permanente e uma conversão em áreas de menor resiliência que condicionam um maior impacto e uma alta sensibilidade.

O zoneamento pedo-hidrográfico permite visualizar o município num contexto de gestão territorial por meio de um enfoque ecossistêmico e de uma visão qualitativa dos potenciais e fragilidades.

\section{AGRADECIMENTOS}

Os autores agradecem a Universidade Federal de Viçosa (UFV) pelo apoio ao desenvolvimento da pesquisa. Ao Núcleo de Estudo e Planejamento do Uso da Terra (NEPUT/UFV) pelo apoio financeiro, a Secretária de Meio Ambiente do Estado do Acre (SEMA) pela logística de campo e disponibilização de dados e a Empresa Brasileira de Pesquisa Agropecuária (Embrapa) pelo apoio nas análises laboratoriais.

\section{REFERÊNCIAS}

ACRE. Secretaria do Meio Ambiente. Programa estadual de zoneamento ecológicoeconômico do Acre, Fase I. Rio Branco, 2000. 250p.

ACRE. Secretaria do Meio Ambiente. Programa estadual de zoneamento ecológicoeconômico do Acre, Fase II. Documento síntese - Escala de 1:250.000. Rio Branco, 2006. $350 \mathrm{p}$.

ACRE. Secretaria do Meio Ambiente. Ordenamento territorial local de Xapuri. Rio Branco, 2010. 202p.

ACRE. Secretaria do Meio Ambiente. Plano estadual de recursos hídricos. Rio Branco, 2012. 123p.

ALMEIDA, J. S.; REIS, V. L.; SILVA, M. M. F. Governança pública das águas: experiência dos estados brasileiros. Salvador: Instituto de Gestão das Águas e Clima, 2009. p. 19-29. (Textos água e ambiente, 4)

ALVES, J. M. P.; CASTRO, P. T. A. Influência de feições geológicas na morfologia da bacia do rio do Tanque (MG) baseada no estudo de parâmetros morfométricos e análises de padrões de lineamentos. Revista Brasileira de Geociências, p. 117-1245, jun. 2003.

BRASIL. Ministério das Minas e Energia. Departamento Nacional de Produção Mineral. Projeto RADAMBRASIL. Folha SC. 19. Rio Branco; geologia, geomorfologia, pedologia, vegetação, uso potencial da terra. Rio de Janeiro, 1976. 458 p. (Levantamento de Recursos Naturais, 12).

CARDOSO, C. A.; DIAS, H. C. T.; SOARES, C. P. B.; MARTINS, S. V. Caracterização morfométrica da bacia hidrográfica do rio Debossan, Nova Friburgo, RJ. Revista Árvore, v. 30, n. 2, p. 241-248, 2006. http://hdl.handle.net/123456789/11425

CHRISTOFOLETTI, A. Geomorfologia. São Paulo, Universidade de São Paulo, 1974. 149 p. 
CHRISTOFOLETTI, A. Modelagem de sistemas ambientais. São Paulo, Universidade de São Paulo, 1999. 236 p.

DEMATTÊ, J. A. M.; DEMÉTRIO, V. A. Fotointerpretação de padrões de drenagem em amostras circulares na caracterização de solos basálticos do estado do Paraná. Revista Brasileira de Ciência do Solo, v. 20, n. 1, p. 109-115, 1996.

HYAMS, D. Curve expert 1.37: a curve fitting system for Windows. Seattle: Microsoft, 1995.

INSTITUTO BRASILEIRO DE GEOGRAFIA E ESTATÍSTICA - IBGE. População recenseada e estimada, segundo os municípios - Acre. Rio de Janeiro, 2010.

MACÊDO, M. N. C. Caracterização hidroambiental e sociocultural da bacia hidrográfica do Riozinho do Rôla, região sudeste do Estado do Acre. 2010. 177f. Tese (Doutorado em Ciência Florestal) - Universidade Federal de Viçosa, Viçosa - MG, 2010.

MACÊDO, M. N. C.; ARAÚJO, E. A.; DIAS, H. C. T.; COELHO, F. M. G.; SOUZA, M. L. H.; SILVA, E. Precipitação pluviométrica e vazão da bacia hidrográfica do Riozinho do Rôla, Amazônia Ocidental. Revista Ambiente \& Água, v. 8, p. 206-221, 2013. http://dx.doi.org/10.4136/ambi-agua.809

MANZOLI Jr., W. Unidades de solos caracterizadas por ocupação, rede de drenagem e relevo de bacias hidrográficas no município de Sud-Mennucci, São Paulo. 1990. 127f. Tese (Doutorado) - Universidade Estadual Paulista, 1990.

PISSARRA, T. C. T.; POLITANO, W.; FERRAUDO, A. S. Avaliação de características morfométricas na relação solo superfície da bacia hidrográfica do córrego rico, Jaboticabal (SP). Revista Brasileira de Ciência do Solo, v. 28, p. 297-305, 2004. http://dx.doi.org/10.1590/S0100-06832004000200008

RANZANI, G. Erodibilidade de alguns solos do Estado do Amazonas. Revista Acta Amazônica, v. 10, n. 2, p. 263-269, 1980.

RESENDE, M.; CURI, N.; REZENDE, S. B.; CORRÊA, G. F. Pedologia: base para distinção de ambientes. Lavras: UFLA, 2007. 322 p.

REZENDE, M.; MACHADO, R. P. Cotas fluviométricas do rio Acre: suas causas e implicações na política de colonização. Revista Acta Amazônica, v.18, n. 3-4, p.85-92, 1998.

SANTOS, R. D.; LEMOS, R. C.; SANTOS, H. G.; KER, J. C.; ANJOS, L. H. C. SHIMIZU, S. H. Manual de descrição e coleta de solo no campo. 6. ed. revista e ampliada Viçosa, Sociedade Brasileira de Ciência do Solo, 2013, 100 p.

SCHAEFER, C. E. G. Clima e paleoclima do Acre: memórias e cenários da aridez quaternária na Amazônia e implicações pedológicas. In: REUNIÃO BRASILEIRA DE CLASSIFICAÇÃO E CORRELAÇÃO DE SOLOS, 9., 2013, Brasília. Guia de campo... Brasília: Embrapa, 2013. p. 60-79.

SENA, J.; FREITAS, M.; BERREDO, D.; FERNANDES, L. Evaluation of vulnerability to extreme climatic events in the Brazilian Amazonia: methodological proposal to the rio Acre Basin. Water Resources Management, New York, v. 26, n. 15, p. 4553-4568, 2012a. http://dx.doi.org/10.007/s11269-012-0166-2 
SENA, J.; BESER DE DEUS, L.; FREITAS, M.; COSTA, L. Extreme events of droughts and floods in Amazonia: 2005 and 2009. Water Resources Management, New York, v.26, n. 6, p. 1665-1676, 2012b. http://dx.doi.org/10.007/s11269-012-9978-3

SILVA, J. X.; ZAIDAN, R. T. Geoprocessamento e análise ambiental: aplicações. Rio de Janeiro, 2004. 363 p.

STRAHLER A. Quantitative analysis of watershed geomorphology. Transactions-American Geophysical Union, n. 38, p. 913-920, 1957. http://dx.doi.org/10.1029/TR038i006p00913

TEODORO, V. L. I.; TEIXEIRA, D.; COSTA, D. J. L.; FULLER, B. B. O conceito de bacia hidrográfica e a importância da caracterização morfométrica para o entendimento da dinâmica ambiental local. Revista Uniara, v. 20, p. 137-157, 2007.

TONELlO, K.C. Análise hidroambiental da bacia hidrográfica da Cachoeira das Pombas, Guanhães, MG. 2005. 85f. Dissertação (Mestrado em Ciência Florestal) Universidade Federal de Viçosa, Viçosa, MG, 2005.

TONELlO, K. C.; DIAS, H. C. T.; SOUZA, A. L.; RIBEIRO, C. A. A. S.; LEITE, F. P. Morfometria da bacia hidrográfica da Cachoeira das Pombas, Guanhães-MG. Revista Árvore, v. 30, p. 849-857, 2006.

TORRES, J. L. R.; SILVA, S. R. S.; PEDRO, C. A. S.; PASSOS, A. O.; GOMES, J. Q. Morfometria e qualidade da água da microbacia do ribeirão da vida em Uberaba-MG. Global Science and Technology, v. 02, n. 01, p. 01 09, jan/abr. 2009.

TUCCI, C. E. M. Hidrologia: ciência e aplicação. 2. ed. Porto Alegre: ABRH, 1991. 943 p.

VILlELA, S. M.; MATTOS, A. Hidrologia aplicada. São Paulo: McGraw-Hill do Brasil, 1975. $245 \mathrm{p}$. 